\title{
AC 2008-2850: THE METROLOGY TRAINING CRISIS: INDUSTRIAL / EDUCATIONAL PARTNERSHIPS MAY CLOSE THE GAP
}

\section{Mark Lapinskes, Sypris Test \& Measurement Inc}

Mark spent over 20 years in the US Army in the TMDE (Test Measurement and Diagnostic Equipment) field. His jobs ranged from Calibration Technician to Team Chief then finally to Instructor Supervisor in the Calibration School at Keesler AFB, MS. He went with the Army's move to relocate the school to Redstone Arsenal, AL and retired there at Redstone. After a brief tenure with Yulista at the Army Primary Standards Lab at Redstone, he took the position of National Technical Training and Support Mgr with Sypris Test \& Measurement. In this role Mark has worked on projects ranging from writing Interactive Training Programs to performing Quality Assurance Audits to setting up sections in the Primary Physical Dimensional Lab in Orlando FL. In early 2006 he also took on the role of Applications Engineer until mid 2007. He holds degrees both in Electronic Systems Technology and as an Instructor of Technology. Mark currently is a member of the Board of Directors of the NCSL International(an international Metrology organization)and chairs the Financial Resources Committee under the 160 Learning and Development Group. 


\title{
THE METROLOGY TRAINING CRISIS: INDUSTRIAL / EDUCATIONAL PARTNERSHIPS MAY CLOSE THE GAP
}

\begin{abstract}
Traditionally, metrology education from the entry level through the technician level was provided through the military. Technical training as well as on the job training for a 4 to 6 year commitment, provided the technical community with a pool of mid-level, broad-scoped, and high-level specialized applicants. As the military outsourced the metrology jobs to the civilian sector, the need to continue training programs began to diminish and the pool slowly dried up. The supply of qualified technicians was unable to keep up with the demand. An ever-growing need for these skills across a broad scope of industries only worsened the situation. This paper explains the decline in military Metrology training, the attempt to integrate the needed training into colleges and Universities, and Sypris Test \& Measurement Inc.'s (ST\&M) partnership efforts with Central Georgia Technical College and University of Central Florida to meet its Industrial Metrology needs.

Introduction

"Metrology" is the Science of Measurement. It is a small field that is obscure from mainstream Science and Engineering but shares the same principles and theories taught at any institution of higher learning. The function of this small group touches almost every action we do and every transaction we make in our day to day existence. Two such examples of this that are easily related to are grocery shopping and the purchase of gasoline. Nearly every item that is purchased at the grocery store is sold by measurement. The measurements deal with weight and volume. Gasoline is sold by volume. Imagine if these measurements were not controlled or traceable to a National Standard. Let's take that one step further, since the majority of our oil is purchased on the foreign market, and take the National Standard up to a Global Standard. This consistency is what Metrology ensures and the chain of measurements is what Metrologists perform.
\end{abstract}

History: Metrology Technicians Trained by U.S. Military

This small niche in of technicians received the majority of their training through the military. A major training facility was opened in April 1959 at Lowery Air Force Base (AFB), Colorado ${ }^{1}$. Training was conducted there for all branches of the service and many allied foreign nationals. The facility is said to have graduated some 50,000 Metrology students between that date and it's closing in March of $1994^{2}$. At that time the curriculum was approximately 37 weeks long. This major Department of Defense (DOD) School transferred the course to Keesler AFB, Mississippi and opened its doors to students again 1995. Once again the school was opened as a multiservice school but was training primarily Army and Air Force Students. The Navy and Marine trainees were co-Located on Keesler AFB but they formed a separate facility targeted toward their own needs. In the years between 1995 and 2000 the flow of students continued but at a far reduced rate from that of the Lowery AFB facility. 
In other areas such as follow-on training and advanced level training, financial cutbacks and moves toward privatization and contracting of the Metrology mission began to take their toll. Most of the Army's advanced schooling and the New Equipment Training departments were shut down. Air Force courses were consolidated and trimmed. In short, the depth of training began to suffer and shifted toward OJT rather than formal courses.

In 2007 the Training Personnel Requirement (TPR) for the combined Army and AF school system was approximately 130. In 1983 when the author attended the school at Lowery AFB the TPR was over 1500 .

\section{Current Metrology Programs in Schools}

In looking at the situation as it exists today, there are a handful of schools offering an Associate of Science degree in Metrology with several others incorporating measurement, statistics, and uncertainty classes in their Engineering and Quality curriculums. The numbers of students actually graduating with Metrology Degrees or Metrology emphasis from these institutions in 2006 was approximately 42. Adding the private sector graduates with the military graduates we have a number of approximately 175 . It is needless to point out that 175 candidates will not satisfy the needs of industry for these highly specialized technicians.

\section{Current Metrology Needs}

The need for Metrologists in industry has not declined over the years in sync with the availability of trained technicians. Contrarily, it has grown at an alarming rate, with needs for Metrologists in calibration laboratories, pharmaceuticals, government labs, research and development, aerospace, state weights and measures, and a host of other positions. The gap between education / training and demand has become a major focus throughout the metrology community. The shift from military schooling to the private sector has been a rough road with few successes and many failures. The reasons vary but common ground seems to be shared between the expense of startup and operating a metrology course and obtaining suitable attendance numbers.

The general lack of knowing the term "Metrology" causes it to be a hard sell for institutions to bolster up attendance numbers. Initial introduction to the field among grade school and high school students has been accomplished only by select individuals at science fairs and career day seminars. One reason for this is that the career field was not entered into the U.S. Department of Labor, Standard Occupational Classification (SOC), therefore did not have a formal, presentable career path to offer to students. Without a recognized career path, Metrology isn't being talked about by guidance counselors to younger students to consider as their profession. This problem has been addressed and Metrology should be added to the register in the next publication of the SOC (2010).

\section{Sypris Test \& Measurement Current Needs \& Options}

ST\&M is one of the businesses that have been affected by the turn of events previously described. At the time of this writing ST\&M employed 160 technicians spread among 40 locations. ST\&M, a subsidiary of Sypris Solutions, provides calibration services via 40 fixed 
locations and 10 mobile laboratories. Product test and component test services are offered at 4 fixed locations; hence the need for Metrology trained personnel is never ending to keep up with growth opportunities. In looking at technician supply and demand, ST\&M was forced to come up with a solution to leverage itself against what is becoming a technician employment crisis.

When ST\&M looked into training for entry level personnel it was plain to see the available options. Most options were not feasible solutions for a commercial enterprise. To compare to the military training plan which required nearly a year of intense 8 hour per day classroom and lab training, a company would have to hire an employee and send them to school for a 2 year AAS degree. This option was simply not affordable or practical. A second option was an online Metrology program. The often heard drawback to this program is the lack of a hands-on component. A third option was to develop a full course to be given through the company. Once again this would be very expensive and the downtime of the employee would be excessive.

A fourth option is the "shadowing" of a new employee to a senior technician. This technique works well with a technician that already has a solid foundation of core metrological concepts but does not cover the necessary scholastic material to instill those concepts in an entry level employee. Not only does this method cost the time of the trainee, but also the production time of the senior technician. The result of this option generally is a technician that can complete a task but does not have the conceptual knowledge to analyze or troubleshoot the process should something go wrong. This does not meet the requirements of ISO/IEC 17025, the International Standard used by testing and calibration laboratories. ISO/IEC 17025, section 5.1.2, states that "laboratory management shall ensure the competence of all who operate specific equipment, perform tests and/or calibrations, evaluate results, and sign test reports and calibration certificates. Personnel performing specific tasks shall be qualified on the basis of appropriate education, training, experience and/or demonstrated skills, as required"3.

ST\&M Solution: Industrial/Educational Partnership

In weighing the options and searching for the overall best method to accommodate both the needs of the company and the needs of new trainees, ST\&M selected a combination approach. ST\&M formed a partnership with Central Georgia Technical College (CGTC) to deliver the theoretical and scholastic modules to the trainee through the online training option, and to provide the hands-on task performance support modules in-house. The result of this coordinated approach is graduating a well rounded technician who is task oriented and has the core metrological concepts needed for analytical work and self sufficiency on the job.

The foundation for this training is twofold: first, the CGTC Metrology curriculum and second, the ST\&M Technical Training Task List. The ST\&M Technical Training Task List has each type of measuring equipment broken down into three catagories: use, calibrate, and troubleshoot/repair. The task list is used to apply the hands-on support task with the theoretical class being taught during each CGTC semester. A small portion of the Task List is shown in Figure 1. The grey and yellow are some of the DC and Low Frequency tasks that are performed in most of our labs. The courses shown in blue are online lectures and theoretical in nature. The key to proper support and a good continuity between the hands-on task list and the CGTC Metrology curriculum is placement of the tasks within the class. The trainees are usually 
allocated 4 hours per day to do the CGTC class work online, and then spend 4 hours per day in the lab doing hands-on support work for the theory they are learning. Figure 2 shows a portion of CGTC course, IFC 101 - Direct Current Circuits I. Look at where the curriculum states "DC Test Equipment". As shown, the first section goes over the operation of several pieces of DC measurement equipment. At this time, the trainer would marry the appropriate tasks from the task list to the CGTC Metrology curriculum being studied. The student then goes over the equipment use by performing hands-on measurements. Since the measurement points are created or measured using calibration equipment standards, the "use" of the measurement equipment is being taught as well as the "use" of the calibration equipment standard. With the task lecture portion of the curriculum already completed, the senior technician who teaches the hands-on task requires minimal time to present it. Notice on the curriculum that plenty of practice time is allotted to the trainee. This approach works well in the lab and measurements can be made on state of the art equipment that the trainee will actually be using once proficient in the task. Graduating trainees to perform proficiently on simple tasks such as calibrate an analog multimeter can occur quickly and result in valuable production hours for the lab during times that are available in the training schedule.

A quick snapshot once again is seen in figure 3. During this course the hands-on segments will cover the tasks of "use" a sine wave generator, "use" a multimeter for AC measurement, and "use" an oscilloscope. Many of the measurements will be monitored or generated by measurement equipment standards, which also support and move on to the "calibrate" portion of the training.

Thus far, although the program is just beginning its second year, the students hired under the program have become valued members of the ST\&M team. These students have contributed both in the calibration and testing services offered by ST\&M. In some areas they are already maintaining a production level and helping with projects that are increasing ST\&M capabilities.

ST\&M partnership efforts also include the University of Central Florida. ST\&M created a summer internship program and hires students from the Electrical and Mechanical Engineering programs. In this internship there have been several Electrical and Mechanical Engineering students that were introduced to Metrology as a profession. 


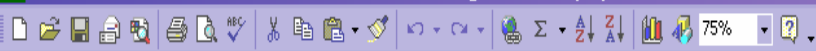

国 Ele Edit View Insert Forrmat Iools Data window Help Adobe PDF

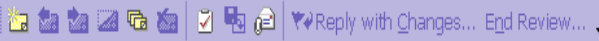

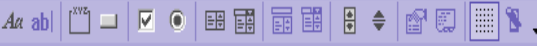

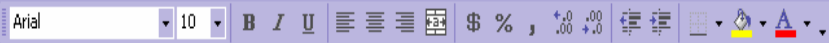

182.13. $\mathrm{K} 1$

$f_{x}$

\begin{tabular}{lr|r|r|r}
1 & NAME: & B & \\
2 & LOCATION: & \\
\hline
\end{tabular}

Select

3

\begin{tabular}{|c|c|c|}
\hline Select & Course Number & Task \\
\hline$\square_{\text {Sdest }}$ & C.INTRO-01.Primer & Intro- Electronic Principles (USAF EP Course) \\
\hline$\square_{\text {Selest }}$ & C-INTRO-02-Primer & Intro- Introduction to Measurement and Calibration \\
\hline
\end{tabular}

\begin{tabular}{l|l|l|l}
\hline & $\square_{\text {Selest }}$ & C.NITRO-03.Primer & Intro-Precision Electrical Measurement
\end{tabular}

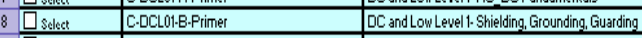

\begin{tabular}{l|l|l}
\hline$\square_{\text {Solest }}$ & C.DCLO1.C.Primer & DC and Low Level $1 . D C n L$ Low; Cables, Usen Effects \\
\hline
\end{tabular}

10 पuse

C.DCLO1-01-Callibrate

Basoir

Ques

Calibret

Rese

Coslibrate

$\square_{\text {Bansi }}$

19 पuse

20 Colibrate

${ }_{22} \square_{\text {Bassir }}$

$23 \square$ Colibrat

$24 \square_{\text {Barsir }}$

25 Use

26 Collibrate

28 Uas

29 Colibrot

$30 \square$ Repir

$31 \square$ Ues

32 प Use

$33 \square$ Colibroste

$34 \square_{\text {Bavi }}$

36 Colibrote

${ }_{38}{ }_{38} \square_{\text {Bassi }}$

$39 \square$ Collibrote

40 Barin

$41 \overline{D_{06}}$

$42 \square$ Colibrote

$43 \square_{\text {Bassir }}$

$44 \square$ Sedu

$45 \square$ U.8

46 Colibro

${ }_{48}{ }_{48} \square_{\text {Babsi }}$

${ }_{49}^{48} \square$ Costibrate

$51 \bar{\square}$ Use

$52 \square$ Colibrate

$53 \square_{\text {Bassit }}$

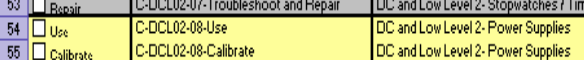
C.DCL01-01-Troubleshoot and Repair

DC and Low Level 1-Basic Resistance to Include Decade Resistor

DC and Low Level 1-Basic Resistance to Include Decade Resistors

C.DCL01.02-Use

DC and Low Level 1 -Basic Resistance tolnolude Decade Resistors

C.DCL01.02.Calibrate

DC and Low Level 1- Null Detectors

$\mathrm{DC}$ and Low Level 1 - Null Detectors

DCL1-03-Calibrate $\quad$ DC and Low Level 1-Analog Multimeters

\begin{tabular}{ll} 
C.OCL01-03.Troubleshoot and Repair & DC and Low Level 1. Analog Multimeters \\
\hline
\end{tabular}

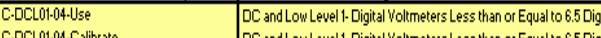

C.DCL01-04-Calibrate $\quad$ DC and Low Level 1 . Digital Yoltmeters Less than or Equal to 6.5 Digit

C.DCL01-04-Troubleshoot and Repair $\quad$ DC and Low Level 1. Digital voltmeters Less than or Equal to 6.5 Digi

C.DCL101.05.Use

C.DCL101.05-Callibrate

DC and Low Level 1-Inductors, Decade Inductors

C.DCLO1-06.Use

DC and Low Level 1 - Capacitor___Decade Capacitor

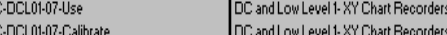

\begin{tabular}{ll} 
C.DCLO1-07-Troubleshoot and Riepair & DC and Low Level 1.XY Chart Recorders \\
\hline
\end{tabular}

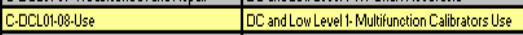

\begin{tabular}{l|l} 
C.DCL02.01-Use & DC and Low Level 2.Clamp-on Ammeters \\
C.DCL02-01-Callbrate & DC and Low Level2-Clamp-on Ammetrs
\end{tabular}

C.DCL02.01.Troubleshoot and Repair DC and Low Level2. Clamp-on Ammeters

\begin{tabular}{l|l} 
C.DCL02-02-Use & DC and Low Level 2. Transconductance Amplifiers
\end{tabular}

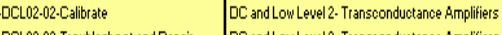

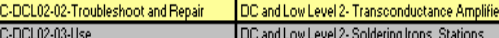

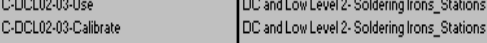

C.DCL02-03-Troubleshoot and Repair $\quad$ DC and Low Level2-Solderinglions_Station

C.DCL02.04.Use

DC and Low Level 2. LCRMeter

C.DCL02-04-Troubleshoot and Repair DC and Low Level 2.LCR Meter

\begin{tabular}{l|l} 
C.DCL02.05-Primer & $D C$ and Low Level2 2 Acoustics and Vibration \\
\hline
\end{tabular}

C.DCL $02.05 \cdot 1$.15e

C.CL102055-Calibrate

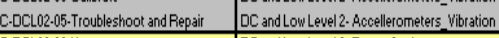

\begin{tabular}{l|l} 
C.DCL02.06-Use & DC and Low Level 2. Power Analyzers
\end{tabular}

C.DCL02.06-Callibrate $\quad D C$ and Low Level 2-Power Analyzers

C.DCL02-06-Troubleshoot and Repair $\quad$ DC and Low Level 2. Power Analuzers

C.0CL02.07-Use

$\mathrm{DC}$ and Low Level 2.Power Analyzers

C.DCL02.07-Calibrate

C.DCLO2-07-Troubleshoot and Repair

DC and Low Level 2-Stopwatches $I$ Timers

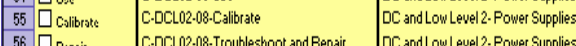

if + 1 Master Course Catalog

Ready

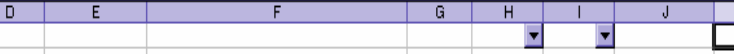

\begin{tabular}{|c|c|c|c|c|c|c|}
\hline $\begin{array}{l}\text { lemploye } \\
\text { e Course } \\
\text { Levels }\end{array}$ & $\begin{array}{l}\text { Delivery } \\
\text { Method }\end{array}$ & Training Materials & Duration & $\begin{array}{c}\text { Class to } \\
\text { Suppt }\end{array}$ & $\begin{array}{c}\text { Propose } \\
\text { d End } \\
\text { Date } \\
\end{array}$ & Instructor \\
\hline 1 & Online Download & STM Tng Pg GOV C.INTRO-01 & selpace & & & mlapinskes \\
\hline 1 & Online & STM TngPg WPT 1001 & 4 hours & MTR III & & mlapinskes \\
\hline 1 & Online & STM TngPgWFT 1002 & 6hours & MTR ili & & mlapinskes \\
\hline 1 & Online & STM TngPgWPT 2021 & 10 hours & MTR131 & & mlapinskes \\
\hline 1 & Online & STM Tng Pg OEMC-DCLO1-B & 2 hours & & & mlapinskes \\
\hline 1 & Online & STM Ting Pg OEMC-DCLOT-C & 2 hours & & & mlapinskes \\
\hline 114 & OJT & & & $\mathrm{FCC} 101$ & & \\
\hline 114 & O.JT & & & MTR131 & & \\
\hline 114 & OJT & & & & & \\
\hline 114 & OJT & & & & & \\
\hline 114 & $0 . \mathrm{JT}$ & & & & & \\
\hline 144 & $0 . J T$ & & & & & \\
\hline 114 & $0 . \mathrm{JT}$ & & & IFC 101 & & \\
\hline 114 & $0 . \mathrm{JT}$ & & & FC 101 & & \\
\hline 114 & OJT & & & & & \\
\hline 114 & OJT & & & IFC 101 & & \\
\hline 114 & $0 . \mathrm{JT}$ & & & FC 101 & & \\
\hline 114 & $0 . \mathrm{JT}$ & & & & & \\
\hline 114 & OJT & & & $\mathrm{FCC} 102$ & & \\
\hline 114 & OJT & & & $\mathrm{FCC} 102$ & & \\
\hline 114 & $0 . \mathrm{JT}$ & & & & & \\
\hline 114 & $0 . \mathrm{JT}$ & & & $\mathrm{FCC} 102$ & & \\
\hline $1 / 4$ & OJT & & & $\mathrm{FC} 102$ & & \\
\hline 114 & $0 . \mathrm{JT}$ & & & & & \\
\hline 114 & OJT & & & & & \\
\hline 114 & OJT & & & & & \\
\hline 114 & $0 . \mathrm{JT}$ & & & & & \\
\hline 114 & OJT & & & IFC 101 & & \\
\hline 114 & OJT & & & FC 101 & & \\
\hline 114 & OJT & & & IFC 101 & & \\
\hline 114 & O.JT & & & & & \\
\hline 114 & $0 \mathrm{JT}$ & & & FCC 101 & & \\
\hline 114 & $0 . \mathrm{JT}$ & & & & & \\
\hline 114 & $0 . \mathrm{JT}$ & & & & & \\
\hline 114 & OJT & & & & & \\
\hline 114 & OJT & & & & & \\
\hline 114 & $0 . \mathrm{JT}$ & & & & & \\
\hline $1 / 4$ & OJT & & & $\mathrm{FCC} 102$ & & \\
\hline 114 & $0 . \mathrm{JT}$ & & & FC 102 & & \\
\hline 114 & $0 . \mathrm{JT}$ & & & & & \\
\hline 1 & Online & STM TngPgWPT 2016 & 10 hours & MTR III & & mlapinskes \\
\hline 114 & $0 . \mathrm{JT}$ & & & & & \\
\hline 114 & $0 . \mathrm{JT}$ & & & & & \\
\hline 114 & OJT & & & & & \\
\hline 114 & $0 . \mathrm{JT}$ & & & & & \\
\hline 114 & $0 . \mathrm{JT}$ & & & & & \\
\hline 114 & $0 . \mathrm{JT}$ & & & & & \\
\hline 114 & $0 . \mathrm{JT}$ & & & & & \\
\hline 114 & $0 . \mathrm{JT}$ & & & & & \\
\hline 114 & $0 . \mathrm{JT}$ & & & & & \\
\hline 114 & $0 . \mathrm{JT}$ & & & & & \\
\hline 114 & $0 . \mathrm{JT}$ & & & & & \\
\hline 114 & $0 . \mathrm{JT}$ & & & & & \\
\hline
\end{tabular}

Fig 1 
Course Guide

\begin{tabular}{|c|c|c|c|c|}
\hline \multirow[b]{2}{*}{ Competency } & \multirow[b]{2}{*}{$\begin{array}{l}\text { After completing this section, the student } \\
\text { will: }\end{array}$} & \multicolumn{3}{|l|}{ Hours } \\
\hline & & \multirow{2}{*}{$\begin{array}{l}\text { Class } \\
10 \\
\end{array}$} & \multirow{2}{*}{$\begin{array}{l}\text { D.Lab/ } \\
\text { P.Lab } \\
0\end{array}$} & \multirow{2}{*}{$\begin{array}{l}\text { Sypris } \\
\text { Supt } \\
0\end{array}$} \\
\hline \multicolumn{2}{|c|}{ ELECTRICAL PRINCIPLES AND LAWS } & & & \\
\hline \multirow[t]{4}{*}{$\begin{array}{l}\text { Voltage, current, } \\
\text { conductance, resistance, and } \\
\text { power }\end{array}$} & $\begin{array}{l}\text { Define voltage, current, power, resistance, } \\
\text { and conductance. }\end{array}$ & & & \\
\hline & $\begin{array}{l}\text { Read and interpret color codes to identify } \\
\text { resistors. }\end{array}$ & & & \\
\hline & $\begin{array}{l}\text { Calculate resistance, conductance, } \\
\text { voltage, current, and power. }\end{array}$ & & & \\
\hline & Define and draw simple resistive circuits. & & & \\
\hline Definitions & $\begin{array}{l}\text { Define basic terms used to describe } \\
\text { electronics quantities, components, } \\
\text { devices, circuits, and systems. }\end{array}$ & & & \\
\hline Symbols & $\begin{array}{l}\text { Identify the symbols associated with basic } \\
\text { electronic components and devices. }\end{array}$ & & & \\
\hline \multicolumn{2}{|l|}{ BATTERIES } & 2 & 1 & 0 \\
\hline Polarity & $\begin{array}{l}\text { Explain the concept of polarity as it applies } \\
\text { to batteries. }\end{array}$ & & & \\
\hline Testing cells and batteries & $\begin{array}{l}\text { Perform a power test of various wet and } \\
\text { dry cells and batteries. }\end{array}$ & & & \\
\hline \multicolumn{2}{|l|}{ DC TEST EQUIPMENT } & 5 & 5 & 61 \\
\hline $\begin{array}{l}\text { Voltmeter, ohmmeter, } \\
\text { ammeter, analog multimeter, } \\
\text { and digital multimeter }\end{array}$ & $\begin{array}{l}\text { Explain the basic operating principles of a } \\
\text { voltmeter, ohmmeter, ammeter, analog } \\
\text { multimeter, and digital multimeter. }\end{array}$ & & & 8 \\
\hline Sypris Task Completion & $\begin{array}{l}\text { Sypris Task: C-DCL01-08-use Multifunction } \\
\text { Calibrator to include all preliminary daily } \\
\text { calibrations and prep procedures if } \\
\text { applicable }\end{array}$ & & & 4 \\
\hline Sypris Task Completion & $\begin{array}{l}\text { Sypris Task: C-DCL02-02-use } \\
\text { Transconductance Amplifier }\end{array}$ & & & 1 \\
\hline Sypris Task Completion & $\begin{array}{l}\text { Sypris Task: C-DCL01-01-Basic } \\
\text { Resistance to Include Decade Resistors }\end{array}$ & & & 1 \\
\hline Sypris Task Completion & $\begin{array}{l}\text { Sypris Task: C-DCL01-03-use Analog } \\
\text { Multimeter }\end{array}$ & & & 1 \\
\hline Sypris Task Completion & $\begin{array}{l}\text { Sypris Task: C-DCL01-04-use Digital } \\
\text { Multimeter < 6.5 Digits }\end{array}$ & & & 2 \\
\hline Sypris Task Completion & $\begin{array}{l}\text { Sypris Task: C-DCL02-01-use Clamp on } \\
\text { Ammeter }\end{array}$ & & & 1 \\
\hline Measuring & $\begin{array}{l}\text { Measure circuit voltage, current, and } \\
\text { resistance. }\end{array}$ & & & 40 \\
\hline \multirow[t]{2}{*}{ Sypris Support } & $\begin{array}{l}\text { Using Multifunction calibrator for } \\
\text { measurements }\end{array}$ & & & \\
\hline & $\begin{array}{l}\text { to also learn the calibration of multimeters } \\
\& \text { ammeters }\end{array}$ & & & \\
\hline Sypris Task Completion & $\begin{array}{l}\text { Sypris Task: C-DCL01-03-calibrate Analog } \\
\text { Multimeter }\end{array}$ & & & 1 \\
\hline
\end{tabular}

Fig 2 
Course Guide

\begin{tabular}{|c|c|c|c|c|}
\hline \multirow[b]{2}{*}{ Competency } & \multirow[b]{2}{*}{ After completing this section, the student will: } & \multicolumn{3}{|l|}{ Hours } \\
\hline & & Class & $\begin{array}{l}\text { D.Lab/ } \\
\text { P.Lab }\end{array}$ & $\begin{array}{l}\text { Sypris } \\
\text { Support }\end{array}$ \\
\hline \multicolumn{2}{|l|}{ MAGNETISM } & 2 & 1 & \\
\hline \multirow[t]{2}{*}{ Magnetism } & Explain the principles of magnetism. & & & \\
\hline & Demonstrate magnetic principle application. & & & \\
\hline \multicolumn{2}{|c|}{ AC WAVE GENERATION } & 2 & 1 & 5 \\
\hline Sine wave & $\begin{array}{l}\text { Describe sine waves generated by alternating } \\
\text { current. }\end{array}$ & & & \\
\hline Alternating current & Define alternating current. & & & \\
\hline $\begin{array}{l}\text { Voltage and current } \\
\text { values }\end{array}$ & Measure AC voltage and current values. & & & \\
\hline $\begin{array}{l}\text { Alternating voltage } \\
\text { generator }\end{array}$ & Describe basic AC generator principles. & & & \\
\hline Sypris Task Completion & Sypris Task: C-RF02-22-Use Audio Oscillator & & & 2 \\
\hline Sypris Task Completion & Sypris Task: C-RF02-02-Use Function Generator & & & 3 \\
\hline \multicolumn{2}{|l|}{ AC TEST EQUIPMENT } & 6 & 4 & 27 \\
\hline Oscilloscope use & Explain oscilloscope control functions. & & & \\
\hline \multirow[t]{2}{*}{ Frequency and period } & $\begin{array}{l}\text { Calculate and measure AC sine wave frequency } \\
\text { and period. }\end{array}$ & & & \\
\hline & $\begin{array}{l}\text { Use an oscilloscope for sinusoidal wave form } \\
\text { voltage, period, and/or frequency measurements. }\end{array}$ & & & \\
\hline Sypris Task Completion & $\begin{array}{l}\text { Sypris Task: C-OS01-02-Use Oscilloscope } \\
\text { Calibrator }\end{array}$ & & & 5 \\
\hline Sypris Task Completion & $\begin{array}{l}\text { Sypris Task: C-OS01-01-Use Oscilloscope Less } \\
\text { than or equal to } 1 \mathrm{Ghz}\end{array}$ & & & 2 \\
\hline Sypris Task Completion & $\begin{array}{l}\text { Sypris Task: C-OS01-01-Calibrate Oscilloscope } \\
\text { Less than or equal to } 1 \mathrm{Ghz}\end{array}$ & & & 20 \\
\hline
\end{tabular}

Fig 3

\section{Summary}

Metrology Training is becoming the responsibility of the private sector. The once fat source of this training, the US Military, has all but been shut off, creating a gap between the supply and demand of Metrology trained technicians. Sypris Test \& Measurement has implemented an internal training program, along with a partnership with Central Georgia Technical College to train entry level technicians in an effort to maintain it's breadth of service, commitment to quality and to expand services in the future. This is one plan to curb the existing technician gap, and ST\&M's commitment to the Metrology community and to Metrology's future.

Bibliography 
${ }^{1}$ Bagley, J. Lyle, Metrology Education in the New Millennium 4-20-2000

${ }^{2}$ Article $\underline{w w w . p m e l . o r g / p m e l h i s t o r y . h t m}$

${ }^{3}$ International Standard ANS/ISO/IEC 17025, Second edition 2005-5-15 